\title{
VARIAÇÃO DA TEMPERATURA DO SOLO NO LESTE DA AMAZÔNIA
}

\author{
Lana Patrícia Martins Nunes ${ }^{(a)}$, Josiane Sarmento dos Santos ${ }^{(\mathrm{b})}$ Suzianny Cristina Salazar Silva ${ }^{(\mathrm{c})}$ \\ Marcia Aparecida Pimentel ${ }^{(\mathrm{d})}$
}

(a) Instituto de Geociências, Programa de Pós-graduação em Ciencias Ambientais, UFPA, lanapnunes@gmail.com

(b) Instituto de Geociências, Programa de Pós-graduação em Ciencias Ambientais, UFPA, josi_met@yahoo.com.br

(c) Instituto de Geociências, Faculdade de Meteorologia, UFPA, suziannysalazar@gmail.com

(d) Instituto de Filosofia e Ciências Humanas/Faculdade de Geografia e Cartografia, UFPA, mapimentel@ufpa.br

\section{Eixo: GEOTECNOLOGIAS E MODELAGEM ESPACIAL EM GEOGRAFIA FÍSICA}

\begin{abstract}
Resumo/
O presente trabalho constitui em um estudo de caso aplicado ao município de Belém /PA. O tema central do estudo consiste no monitoramento da qualidade ambiental a partir da análise do Índice de Vegetação por Diferença Normalizada (NDVI) e a temperatura da superfície, utilizando para isto técnicas de geoprocessamento. Os resultados mostram que uma relação inversa entre a temperatura da superfície e o NDVI, com diferenças significativas entre os bairros mais arborizados e os menos. E devido ao fato do ano de 2015 ter sido influenciado pelo fenômeno El Niño, a temperatura do ar esteve acima da normal climatológica.
\end{abstract}

Palavras chave: Clima Urbano, El Nino, Sensoriamento remoto, NDVI, Belém/PA.

\section{Introdução}

A urbanização constitui um dos processos que mais alteram não somente a morfologia do terreno, mas também as características ambientais, sociais e climatológicas (Dorigon, 2014). Parte desse processo contribui, não somente para o aumento da concentração populacional e deficiência na infraestrutura para atender o contingente populacional em expansão, mas também, para a supressão de áreas verdes e substituição da cobertura do solo, resultando em um aumento geral da temperatura da paisagem, criando um clima próprio ou urbano (Monteiro e Mendonça, 2011). Seus efeitos são sentidos pela população através da alteração do conforto térmico, da qualidade do ar, além de outras manifestações, deteriorando a qualidade de vida dos habitantes (MENDONÇA e DANNI-OLIVERIA, 2007 apud COELHO, 2013).

No município de Belém, o processo de urbanização não tem sido diferente. A concentração populacional no ambiente urbano tem proporcionado diversos problemas ambientais e sociais resultantes das atividades econômicas, expansão do espaço construído e falta de planejamento adequado que considere os fatores ambientais e socioeconômicos. Os ambientes construídos atrelados à redução da cobertura vegetal, sugere alteração nas temperaturas tanto do ar como da superfície em escala local. As disponibilidades de informações relativas aos aspectos climáticos de um dado lugar são de suma importância, uma vez que o 
clima é um fator determinante para o ser humano, e sendo por este modificado, deveria ser levado em consideração no que diz respeito ao planejamento urbano.

Dados de temperatura da superfície e Índice de Vegetação por Diferença Normalizada são obtidos através de técnicas de geoprocessamento, podem ser relacionados com estudos de clima urbano e configuram-se como indicadores importantes auxiliando nas análises de qualidade ambiental urbana (LIMA, 2011).

Neste sentido, o sensoriamento remoto, através da temperatura da superfície e do mapeamento da vegetação, tem sido usado com grande frequência, uma vez que as imagens de satélite podem ajudar a compreender a distribuição espacial das fontes de calor dentro de uma área urbana que levam à formação das ilhas de calor urbanas - ICU (DORIGON, 2014).

A temperatura da superfície, bem como, o Índice de Vegetação por Diferença Normalizada têm sido frequentemente alvo de pesquisas em trabalhos científicos. Pesquisadores como Sobrino, Li e Becker, 1994; Nascimento (2011), Fialho (2012), Souza e Ferreira Júnior (2012), Parizoto et al. (2013) entre outros, também usaram sistemas de sensoriamento remoto com várias aplicações nas áreas da meteorologia, climatologia e estudos de ordem ambiental.

Apoiado em referencias teórico-metodológicos esta pesquisa tem como objetivo utilizar as informações de dados obtidos por meio de técnicas de sensoriamento remoto, como temperatura da superfície e NDVI com dados de temperatura do ar para auxiliar nas análises e monitoramento de qualidade ambiental do município de Belém/PA. As análise e discussões expostas neste artigo fazem parte da pesquisa de doutorado: “Avaliação da Qualidade Socioambiental no município de Belém/PA”.

\section{2. Área de estudo}

A área de estudo compreende a maior parte urbana do município de Belém localizado na região norte do estado do Pará (Figura 1). O município possui uma área aproximada de $1064,918 \mathrm{~km}^{2}$ e situa-se entre as coordenadas geográficas $01^{\circ} 27^{\prime} 21^{\prime}$ 'de latitude $\mathrm{S}$ e $48^{\circ} 30^{\prime \prime} 16^{\prime}$ de longitude W e altitude de 10 metros (SILVA JUNIOR, 2012). 

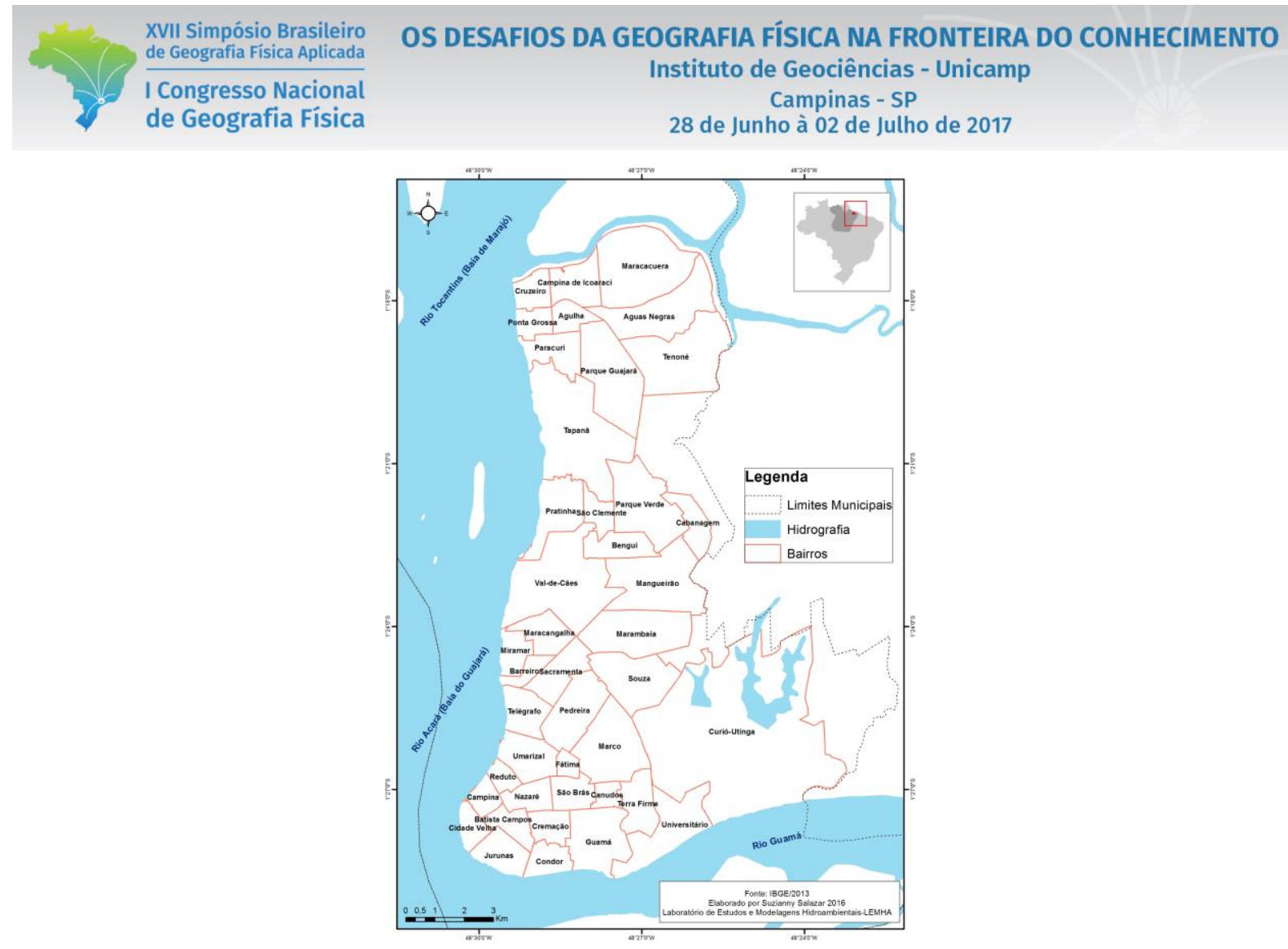

Figura 1 - Localização da área de estudo.

A cidade apresenta problemas sociais e ambientais em sua paisagem que pode ser constatado na literatura e em trabalho de campo realizado em maio de 2016, como ausência de vegetação em alguns bairros, despejo inadequado de resíduos sólidos, falta de saneamento, doenças de veiculação hídrica, entre outros (NUNES et. al. 2016).

\section{Materiais e Métodos}

Para que os objetivos propostos desse estudo fossem alcançados, o mesmo foi dividido em duas fases a saber: $1^{\circ}$ fase: Consistiu na aquisição de referencial bibliográfico selecionado abordando a temática, informações de temperatura do ar, na data de passagem do satélite provenientes do Instituto Nacional de Meteorologia (INMET), da cidade de Belém-Pa dos anos de 2013 e 2015, que serviram de parametrização / comparação com a temperatura de superfície registrada pelo sensor. A $2^{\circ}$ fase consistiu na aquisição de imagens orbitais digitais gratuitas, banda 10, correspondente à faixa do infravermelho termal (10.6 - 11.19 $\mu \mathrm{m}$ - micrômetro), com resolução espacial de 30 metros do satélite Landsat-8 no Serviço de Levantamento Geológico Americano (USGS, 2013), sensor TIRS (Thermal Infrared Sensor), órbita 223, ponto 761, para os anos de 2013 e 2015 para o processamento da temperatura da superfície. As bandas multiespectrais do 
satélite Landsat 8 foram utilizadas as bandas $4(0.64-0.67 \mu \mathrm{m})$ e $5(0.85-0.88 \mu \mathrm{m})$, com resolução de 30 metros do sensor OLI (Operational Land Imager), para a obtenção do NDVI.

O período escolhido para o monitoramento da variável temperatura da superfície e NDVI corresponde ao final período menos chuvoso (julho), quando há pouca presença de nuvens na região, redução das chuvas e aumento da temperatura do ar (FISCH et al., 1996). Os anos selecionados foram escolhidos com base nos eventos de ENOS que são descritos no site da National Oceanic and Atmospheric Administration.

Foi utilizado neste trabalho o Software ArcGis 10.2.2 para a elaboração da carta de temperatura da superfície, bem como, para o cálculo do NDVI.

\subsection{Temperaturas de superfície}

Para a aquisição de dados de temperatura foi feito o recorte da imagem infravermelho termal na área desejada seguido do uso de parâmetros fixos de conversão de níveis de cinza da imagem (NC) para radiância, depois para temperatura em kelvin e convertidas para ${ }^{\circ} \mathrm{C}$ (graus Celsius), com a aplicação da equação equações 1 descrita abaixo:

$$
\mathrm{L} \chi=\mathrm{ML} x \mathrm{Qcal}+\mathrm{AL}
$$

Onde:

Lג Radiância Espectral do sensor de abertura em Watts/( $\mathrm{m} 2 \mathrm{sr} \mu \mathrm{m})$

ML Fator multiplicativo de redimensionamento da banda $10=$ $3.3420 \mathrm{E}-04$

Qcal Fator de redimensionamento aditivo específico da banda $10=$ 0.10000

AL Valor quantizado calibrado pelo pixel em DN = Imagem banda 10

Após a transformação dos valores em radiância aplicou-se a equação 2 com a finalidade de transformar os valores obtidos na primeira, em temperatura de valor em Kelvin:

$$
T=\frac{K 2}{\ln \left(\frac{K 1}{L \lambda}+1\right)}
$$

Onde: 
XVII Simpósio Brasileiro

de Geografia Física Aplicada

I Congresso Nacional

de Geografia Física

$\mathrm{T}$

K2

K1

Lג
OS DESAFIOS DA GEOGRAFIA FÍSICA NA FRONTEIRA DO CONHECIMENTO

Instituto de Geociências - Unicamp

Campinas - SP

28 de Junho à 02 de Julho de 2017

Temperatura efetiva no satélite em Kelvin (K)

Constante de calibração $2=1.321 .08(\mathrm{~K})$

Constante de calibração $1=774.89(\mathrm{~K})$

Radiância espectral em Watts/( m2 sr $\mu \mathrm{m})$

Em seguida, os valores de temperatura Kelvin foram subtraídos pelo seu valor absoluto $(273,15)$, gerando a imagem de temperatura da superfície em graus Celsius $\left({ }^{\circ} \mathrm{C}\right)$. Esses dados foram posteriormente validados com o registro de temperatura do ar da estação meteorológica de Belém, seguido do recorte da imagem com base no limite do objeto de estudo.

2.2 Mapeamento e cálculo do Índice de Vegetação por Diferença Normalizada- NDVI

Para este trabalho, aplicou-se o NDVI com o intuito de mapear as áreas com concentração de vegetação na cidade de Belém/PA de forma a auxiliar nas análises da qualidade ambiental juntamente com as informações de temperatura da superfície e do ar. O NDVI é um indicador sensível da quantidade e condição da vegetação, cujos valores variam no intervalo de -1 a 1 (Boratto \& Gomide, 2013). Os valores próximos a 1 corresponde a densidade de vegetação e valores próximos de 0 considera-se ausência de vegetação, sendo obtidos pela Equação 3:

$$
\mathrm{NDVI}=\frac{\mathrm{IVP}-\mathrm{V}}{\mathrm{IVP}+\mathrm{V}}
$$

Onde:

$$
\begin{aligned}
& \text { IVP } \quad \text { Infravermelho próximo }(\mu \mathrm{m})-\text { banda } 5 \text {; } \\
& \text { V } \quad \text { Vermelho }(\mu \mathrm{m})-\text { banda } 4 \text {. }
\end{aligned}
$$

No software ArcGis 10.2.2 foi organizado o banco de dados e toda integração das informações para o mapeamento do NDVI. Também para efeito comparativo das temperaturas dos anos de 2013 e 2015 foi utilizado o teste $\mathrm{T}$ de student para saber se há diferença significativa da variável entre os anos na cidade.

\subsection{Temperaturas do ar $(\mathrm{oC})$}

Para a validação dos dados de temperatura de superfície foram utilizados a parametrização/comparação dos registros de temperatura do ar da estação meteorológica de Belém adquiridos através do site do Instituto Nacional de Meteorologia (INMET) dos anos de 2013 e 2015. 


\section{Resultados e Discussões}

A Figura 2 mostra a variação espacial da distribuição da temperatura de superfície (Ts) na área urbana de Belém. Os valores de temperatura para os anos de 2013 e 2015 tiveram uma variação de $22^{\circ} \mathrm{C}$ até $32^{\circ} \mathrm{C}$ para o ano de 2013 e de $21^{\circ} \mathrm{C}$ até $33^{\circ} \mathrm{C}$ para o ano de 2015 . Analisando-a, constata-se que nas áreas com tonalidade azul encontram-se as menores temperaturas, as quais variam entre $21^{\circ} \mathrm{C}$ e $28^{\circ} \mathrm{C}$; as áreas com tonalidade verde amarelada representam os valores intermediários da temperatura variando entre $28^{\circ} \mathrm{C}$ até $30^{\circ} \mathrm{C}$, aproximadamente e as áreas com tonalidades em amarelo e vermelho apresentaram os maiores valores de temperatura variando de $30^{\circ} \mathrm{C}$ até $33^{\circ} \mathrm{C}$.

As maiores temperaturas foram registradas no período de 2015 que coincidiu com ano de El Niño Forte (NOAA, 2016). Realizado então o teste $\mathrm{T}$ de student a diferença entre as médias foi significativa com $\mathrm{p}$ valor de 0,8 .
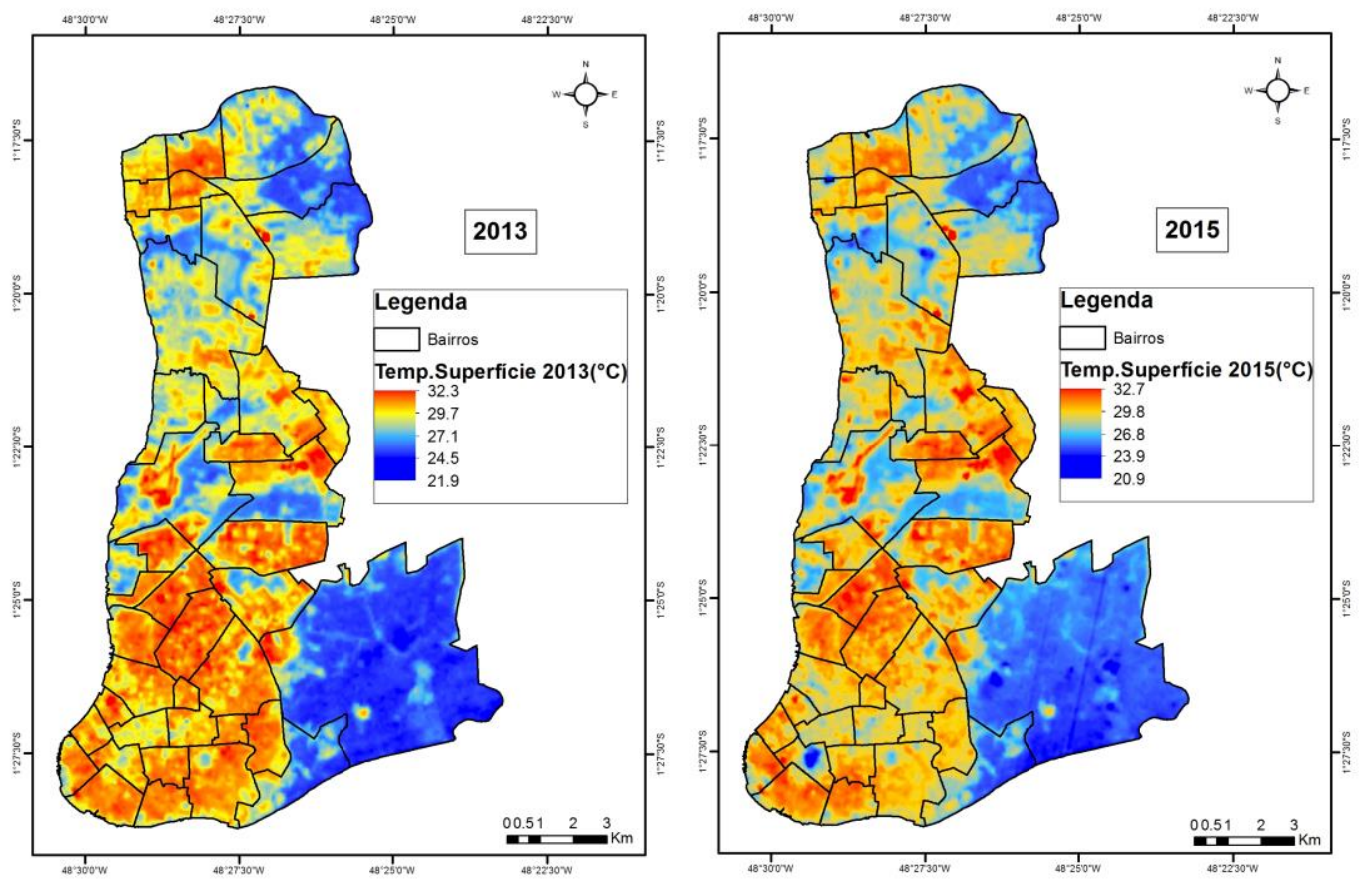

Figura 2 - Cartas de temperatura da superfície da cidade de Belém/PA gerada a partir imagem do infravermelho termal do sensor TIRS do satélite Landsat-8 para os anos de 2013 e 2015.

O dia 27 de julho de 2013 e outros dias do mês de julho do mesmo ano $(15,16,17,21,23,24)$ apresentaram valores de temperatura mínima do ar abaixo da Normal climatológica (1961-1990), isto porque este ano esteve sobre influência do fenômeno La Niña (NOAA, 2016), enquanto que no 2015 para 


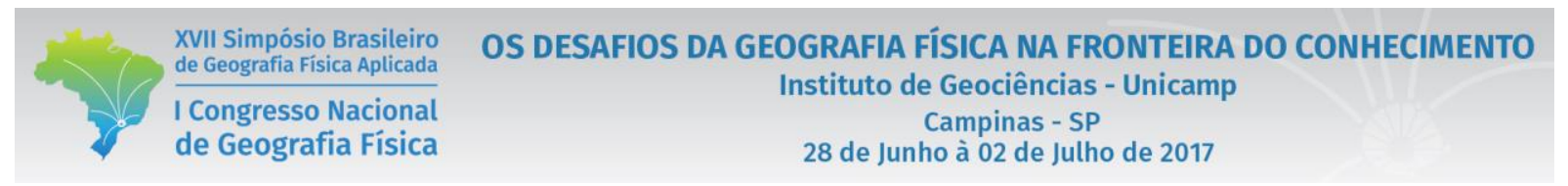

o mesmo mês, todo os valores foram acima Normal climatológica segundo o INMET (2016), fato que pode ser observado nas Figura 3 e Figura 4. Segundo Weng (2003), a temperatura média de superfície apresenta, normalmente, valores mais elevados em relação a temperatura média do ar.

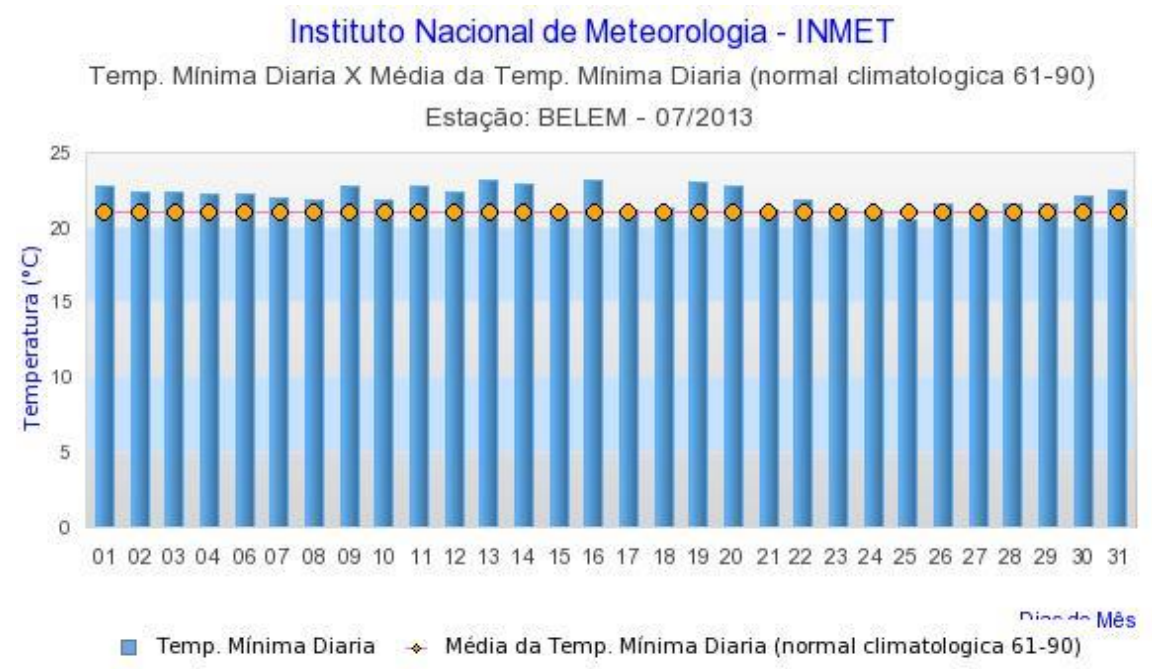

Figura 3 - Variação da Temperatura mínima do ar na cidade de Belém-Pa em julho de 2013.

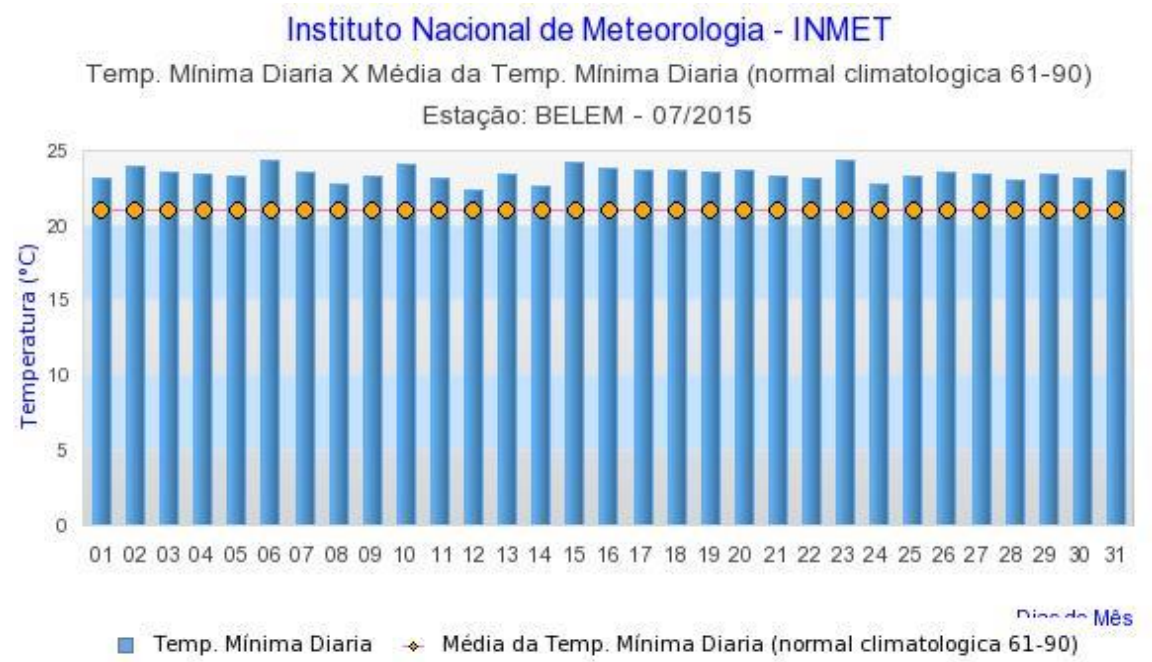

Figura 4 - Variação da Temperatura mínima do ar na cidade de Belém-Pa em julho de 2015

As informações contidas na carta de temperatura da cidade de Belém são resultantes da influência da distribuição espacial da cobertura vegetal como dos tipos de uso do solo na área urbana de Belém.

Os mapas das imagens processadas referentes aos cálculos do NDVI, para dois períodos, 27/07/2013 e 17/07/2015, são mostrados na Figura 5. Os resultados do NDVI, expressam similaridades em relação aos 
resultados obtidos para os dois anos estudados (Figura 5). Verifica-se nas duas imagens que os valores próximos negativos ou próximos desse intervalo do NDVI, estão associados a regiões de água e ausentes de vegetação (cor vermelha; amarela) e os valores positivos representam as áreas com presença de vegetação (cor verde).
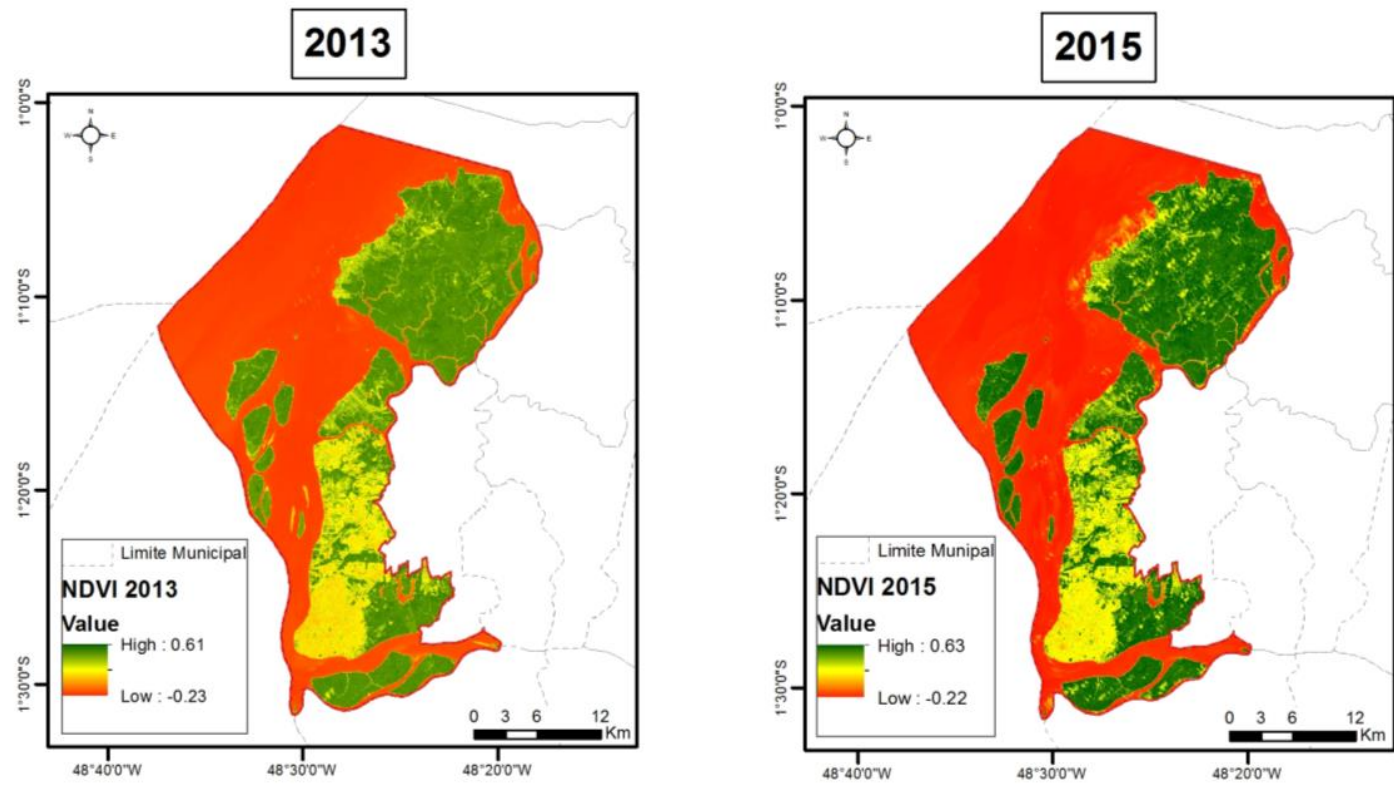

Figura 5 - Índice de Vegetação por Diferença Normalizada do município de Belém/PA gerada a partir das bandas multiespectrais 4 (faixa do vermelho) e 5 (faixa do infravermelho próximo) do sensor OLI do satélite Landsat-8 para os anos de 2013 e 2015.

Deste modo, nota-se que a temperatura da superfície de Belém é resultado direto das áreas que se encontram com e sem vegetação da cidade, uma vez que as respostas das duas cartas apresentaram praticamente a mesma espacialização de temperatura e quantidade de vegetação, ou seja, locais com menores valores de NDVI mostraram maiores temperaturas da superfície, enquanto que áreas com maiores valores NDVI, apresentaram as menores temperaturas.

As áreas que apresentaram as menores temperaturas estão associadas às áreas onde a cobertura vegetal é mais presente, destacando-se o Parque do Utinga Área "A", o Parque do Médici "B", as áreas pertencentes a Marinha Área "C", o Bioparque Amazônia Área "D" e também os corpos hídricos e pequenas praças e resquícios de floresta nativa e floresta secundária espalhados pela cidade que podem ser consideradas como ilhas de amenidade, impedindo o aquecimento da superfície, foram as mesmas áreas tanto no ano de 2013 quanto no ano de 2015. (Figura 6). 


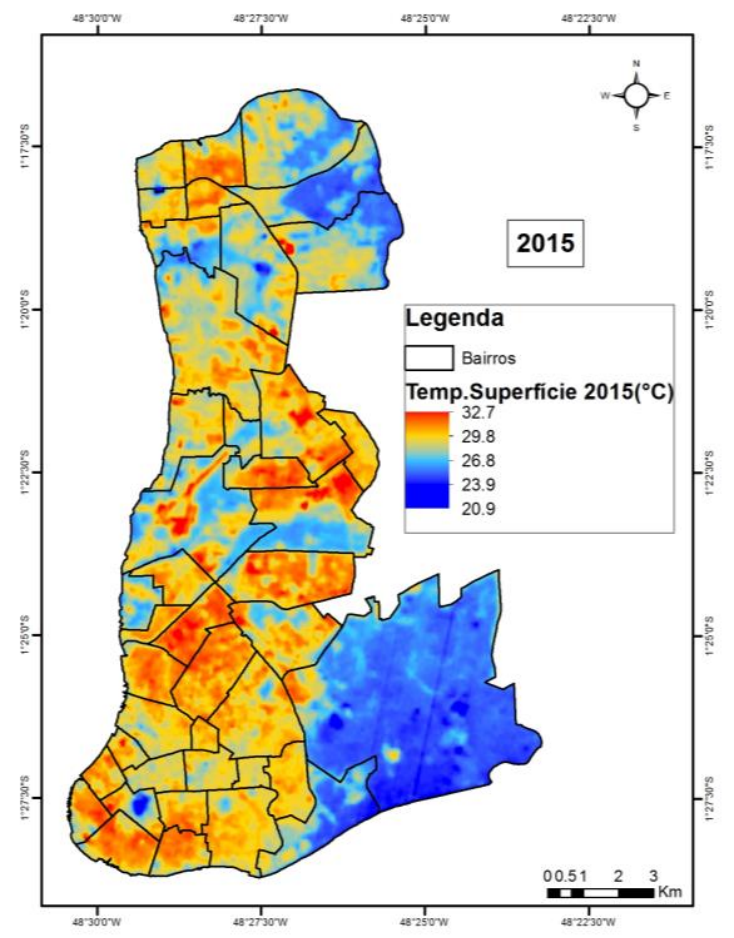

Figura 6 - Relação das Áreas com presença de vegetação e temperatura da superfície no município de Belém/PA.

\section{Considerações Finais}

A temperatura da superfície do solo e do ar apresentaram maiores valores no ano de 2015 devido ao fato deste ano sofrer influência do El Niño, enquanto que no ano de 2013 as temperaturas do solo e do ar foram menores devido a influência da La Niña. Os resultados também mostraram a importância e influência da vegetação para o aumento ou redução da temperatura da superfície do solo ao analisar as regiões com e sem vegetação através do NDVI, pois as áreas mais arborizadas são as que possuíram os menores valores de temperatura da superfície do solo, tanto para o ano de 2013 quanto para o ano de 2015.

\section{Referências}

COELHO, A. L. N.; CORREA, W. S. C. Temperatura de superfície Celsius do sensor TIRS/Landsat-8: Metodologia e Aplicações. Rev. Geogr. Acadêmica v.7, n.1. 2013.

DORIGON, L. P.; AMORIM, M. C.C. T. Técnicas de sensoriamento remoto (Temperatura da superfície e NDVI) aplicadas aos estudos de clima urbano, o exemplo de Paranavaí/PR. Disponível em: http://www.cbg2014.agb.org.br/. Acesso em: 24/07/2016. 
FIALHO, E. S. Estudos Climáticos em Sítios Urbanos e Rurais, (Orgs.) SILVA, Charlei Aparecido da e FIALHO Edson Soares, Concepções e Ensaios da Climatologia Geográfica e-book. ED. UFGD, PP-83-112. 2012.

FISCH, G.; MARENGO, J.A.; NOBRE, C.A. Clima atual da região Amazônica, o. Clima da Amazônia. Climanálise.1996.

IBGE - Instituto Brasileiro de Geografia e Estatística. Disponível em: http://www.inmet.gov.br. Acessado em: $13 / 05 / 2016$.

INMET - Instituto Nacional de Meteorologia. Disponível em: http://www.inmet.gov.br. Acessado em: 13/05/2016.

LIMA, V., AMORIM, M. C. de C. T. A utilização de informações de temperatura da superfície, do NDVI e de temperatura do ar na análise de qualidade ambiental urbana. ANAIS XV SIMPÓSIO BRASILEIRO DE SENSORIAMENTO REMOTO - SBSR, Curitiba, PR, Brasil, 30 de abril a 05 de maio de 2011, INPE p.1028. 2011.

MONTEIRO, C. A. F.; MENDONÇA, F. Clima Urbano. 2a Edição. São Paulo: Contexto, 192 p. 2011.

NASCIMENTO, D. T. F. Emprego de técnicas de sensoriamento remoto e de geoprocessamento na análise multitemporal do fenômeno de ilhas de calor no município de Goiânia-GO (1986/2010). Dissertação (Mestrado em Geografia) - Instituto de Estudos Sociais - Universidade Federal de Goiás, Goiânia, 96f. 2011.

NATIONAL OCEANIC AND ATMOSPHERIC ADMINISTRATION - NOOA. Climate Prediction Center. Disponível em: http://www.cpc.ncep.noaa.gov/products/analysis_monitoring/ensostuff/ensoyears.shtml. Acesso em 01 de julho de 2016.

NUNES, L. P. M. N.; RODRIGUES, G. PIMENTEL, M. A. S.; Impactos Socioambientais na Região Metropolitana de Belém/Pa. Encontro Luso-Afro-Americano de Geografia Física e Ambiente. Maputo. 53 p. 2016.

PARIZOTO, N. M. S. F.; CAMPOS, S.; RODRIGUES, M. T.; TRAFICANTE, D. P.; GARCIA, Y. M. Influência da temperatura de superfície em diferentes setores da área urbana de Piratininga/sp por meio de dados orbitais. Disponível em: http://www.cartografia.org.br/. Acesso em: 26/07/2016.

SOBRINO, J.A.; LI, Z.L.; STOLL, M.P.; BECKER, F. Improvements in the split-window technique for land surface temperature determination. IEE Transaction on Geoscience and Remote Sensing. v. 32, n. 2, p. 243-253. 1994.

SOUZA, S. B. DE; FERREIRA JÚNIOR, L. G. Relação entre temperatura de superfície terrestre, índices espectrais e classes de cobertura da terra no município de Goiânia (GO). Revista Espaço Geográfico em Análise. Vol. 26. Paraná, p. $75-99.2012$.

USGV. Serviço Geológico dos Estados Unidos. Disponível em: http://www.usgv.gov/. Acesso em: 13/05/2016. 


\begin{tabular}{|c|c|}
\hline $\begin{array}{l}\text { XVII Simpósio Brasileiro } \\
\text { de Geografia Fisica Aplicada } \\
\end{array}$ & $\begin{array}{l}\text { OS DESAFIOS DA GEOGRAFIA FÍSICA NA FRONTEIRA DO CONHECIMENTO } \\
\text { Instituto de Geociências - Unicamp }\end{array}$ \\
\hline $\begin{array}{l}\text { I Congresso Nacional } \\
\text { de Geografia Física }\end{array}$ & $\begin{array}{l}\text { Campinas - SP } \\
28 \text { de Junho à } 02 \text { de Julho de } 2017\end{array}$ \\
\hline
\end{tabular}

WENG, Q. Fractal analysis of satellite-detected urban heat island effect. Photogrammetric Engineering and Remote Sensing, Bethesda, v.69. (2003).

\section{Agradecimentos}

O primeiro e segundo autor agradecem a CAPES e a FAPESPA, pela concessão da bolsa Doutorado. 